\title{
A rare vulval lump: a case of superficial angiomyxoma
}

\author{
Widanage $\mathbf{N}^{1}$, Abeygunasekera $\mathrm{N}^{2}$, Wasalaarachchi $\mathrm{KCK}^{3}$, Yapa $\mathrm{C}^{4}$
}

\section{Key words}

Vulva, lump, superficial, angiomyxoma

\section{Introduction}

Patients with vulval lumps are frequently encountered in sexually transmitted diseases (STD) clinics. A wide variety of conditions including venereal as well as non-venereal causes like condylomata lata, genital warts, Bartholin's abscesses, nodular scabies, sebaceous cysts, sebborhoeic keratosis, skin tags and malignancies can present to STD clinics as vulval lumps. It is essential for the clinicians who are managing patients in STD clinics to have a good understanding of the possible differential diagnoses of vulval lumps.

Here, we describe a rare case of superficial angiomyxoma of the vulva presenting to STD clinic, Kalubowila. Less than 20 cases of superficial angiomyxoma of the vulva have been reported world wide as of now. $(1,2)$

\section{Case}

A 42 year old married lady was referred from the gynaecology ward with two progressively enlarging painless lumps in the vulva of 2 years duration. During the last two months there had been a rapid increase in the size of lumps. There was no vaginal discharge, abdominal pain or dyspareunia. However, she did report of having similar lesions in the same site thirteen years ago which had been surgically removed. Her menstrual cycles were regular with no intermenstrual bleeding or post-coital bleeding. She has had two normal vaginal deliveries and there was no history of abortions. She denied ever having premarital or extra marital sexual exposures and the marital partner was asymptomatic.

Examination revealed two large soft, non-tender pedunculated masses arising from the left labia majora measuring $16 \mathrm{~cm} \times 10 \mathrm{~cm}$ and $12 \mathrm{cmx} 8 \mathrm{~cm}$. In addition to these two large lumps there were several much smaller lumps (figure 1). There were a few ulcers and hypopigmented areas on the surface of the larger lesions. STI screening was negative and cervical Papanicolaou smear did not show any abnormality.

Figure 1 : Large pedunculated vulval lumps

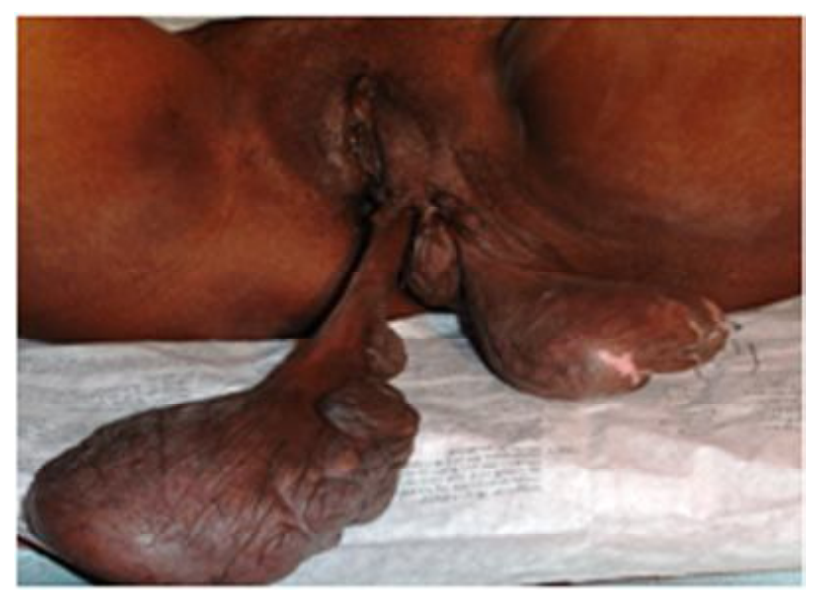

The lumps were surgically excised. The biopsy report stated an oedematous stroma with hypocellular fibrous tissue and myxoid appearances with scattered thin walled blood vessels. There was no cellular atypia or mitoses seen. Foci of adipose tissue were also seen predominantly in the pedicle sections of the excision margin. The conclusion was a benign fibrovascular lesion suggestive of superficial angiomyxoma (figure 2). 
Figure 2: Microscopic appearence; Oedematous stroma with hypocellular fibrous tissue and thin walled blood vessels.

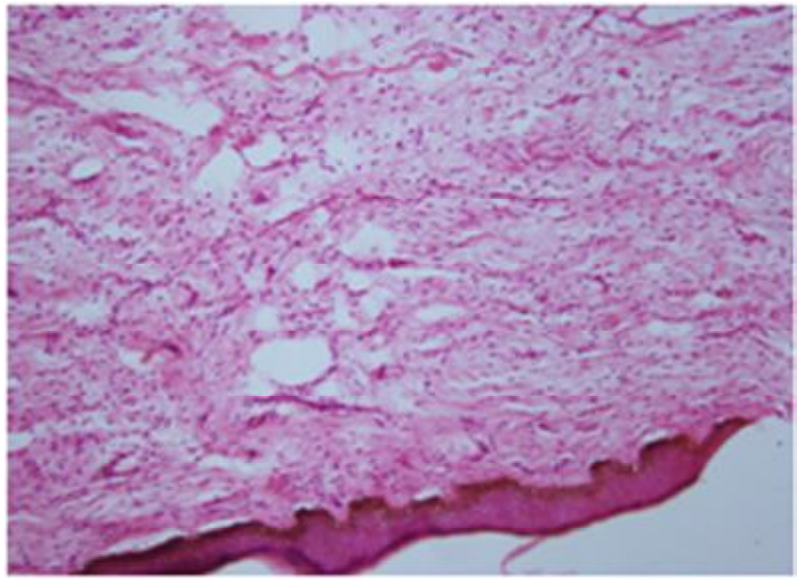

\section{Discussion}

Three types of angiomyxomas have been identified; superficial angiomyxoma (SAM), aggressive angiomyxoma (AAM) and angiomyofibroblastoma (AMFB). SAMs are rare benign cutaneous tumours arising from the dermis or subcutis. It was first described in 1988.(3) SAM is a distinctive clinicopathologic entity that should be included in the differential diagnosis of myxoid cutaneous tumours.

A study done on 17 cases of SAM arising in the genital region found that the predominant reason for seeking medical attention was a slow growing painless mass. Also this study reports the sites of involvement in females were the labium majus ( $n=6)$, vulva $(n=4)$, groin $(n=2)$ and mons pubis $(n=1)$ of the 13 females in the study.(4) Most cases occur in adults as an asymptomatic solitary papule or nodule with equal sex incidence.(5) However, literature review revealed a case of SAM in a three year old girl in Japan.(6)

SAMs are usually less than $3 \mathrm{~cm}$ and have a wide anatomical distribution with apredilection for the trunk, head/neck area and genital skin.(5) The patient we encountered had two large lesions measuring $16 \mathrm{~cm}$ $\mathrm{x} 10 \mathrm{~cm}$ and $12 \mathrm{cmx} 8 \mathrm{~cm}$. Giant superficial angiomyxomas measuring over $10 \mathrm{~cm}$ have been reported and they can mimic aggressive angiomyxoma.(2) As this vulval lump was fairly large the possibility of whether it was an AAM was queried. AAM and SAM can be differentiated histologically and with immuno-histochemical studies. AAMs are often larger, ill-defined measuring $10 \mathrm{~cm}$ or more with extension into deeper tissue and composed of thick walled blood vessels.(5) SAMs are not locally destructive and composed of numerous small blood vessels with sparse spindle shaped cells in a prominent myxoid stroma.(5)Actin and desmin stains are positive in almost all cases of AAMs whereas SAMs are desmin negative.(7) Tumour cells of AAMs are often positive for oestrogen and progesterone receptors.(5) Immuno-histochemical studies were not performed in this case. Local recurrence is common and is seen in up to $30 \%$ of cases when there is incomplete excision of SAMs.(5) This patient too, had similar lesions in the past.

A case of SAM complicated with condylomata accuminatum and staphylococcus hominis has been described.(8) It highlighted the importance of early treatment of SAM as they are composed of small blood vessels in a myxoid stroma where surface ulceration can lead to various secondary infections. Even though there were small ulcers noticed over the lumps in this patient there was no evidence of secondary infection. In patients with multiple lesions the possibility of Carneys' complex comprising of myxomas, lentiginous pigmentation and endocrine abnormalities should be considered.(9) However, in our patient there was no clinical evidence of endocrine abnormalities or skin pigmentations.

\section{References}

1. Basak S, Rogers S, Solomonsz AF. Superficial angiomyxoma of the vulva: A case report of a rare cutaneous tumour. Journal of Obstetrics and Gynaecology 2011; 31: 360-361.

2. Kim HS. Giant superficial angiomyxoma of the vulva: a case report and review of literature. Journal of Cutan eous Pathology 2010 Jun; 37(6):672-7. 
3. Calonje E, Guerin D, McCormick D et al. Superficaial angiomyxoma: clinicopathological analysis of a series of distinctive but poorly recognized cutaneous tumours with the tendency for recurrence. American Journal of Surgical Pathology 1999; 23: 910-917.

4. Fetsh JF, Laskin WB, Tavassoli FA. Superficial angiomyxoma (cutaneous myxoma) a clinicopathologic study of 17 cases arising in the genital region. International Journal of Gynaecological pathology 1997; 16(4): 325-334.

5. Calonje E. Soft tissue tumours and tumour like conditions. In: Burns T, Breathnach S, Cox N, Griffiths C, editors. Rooks Textbook of Dermatology. 8th ed. Wiley-Blackwell; 2010. p. 56-59.

6. Okada Y, Mori H, Tsuji M, Yagi Y. A case of vulvar superficial angiomyxoma with necrotizing angiitislike lesions and expression of granulocyte-colony stimulating factor. Pathology Research and Practice 2005; 201(2):145-152.

7. Kempson RL, Teixeira MR, Hendrickson MR. Mesenchymal tumours. In: Tavassoli FA, Devilee P, editors. WHO Classification of Tumours. Pathology and Genetics of Tumours of the Breast and Female Genital Organs. IARC Press; Lyon 2003. p329.

8. Zhu L, Zhao W, Shi Y, Lin B. Superficial an giomyxoma of the vulva complicated with condyloma accuminatum and staphylococcus hominis infection. International Journal of Dermatology 2013 Jan; doi: 10.1111/j.13654632.2012.05572.x

9. Carney JA, Headington JT. Cutaneous myxomas: a major component of the complex of myxomas, spotty pigmentation and endocrine over activity. Arch Dermatol 1986; 122:790-8. 